\title{
University Students raise Employment Competitive by Personal Knowledge Management
}

\author{
Weiqi $\mathrm{Ma}^{1, \mathrm{a}}$, Yunliang $\mathrm{He}^{2, \mathrm{~b}}$ \\ ${ }^{1}$ Qujing Normal University Qujing Yunnan, 655011,China \\ ${ }^{2}$ Qujing Normal University Qujing Yunnan, 655011,China \\ aemail:maweiqi@21cn.com, bemail:346308591@qq.com
}

Keywords: University student;Personall knowledge management;Employment; Competitive

\begin{abstract}
The employment become a big problem for college students. Students have to enhance their employability and competitiveness, in order to have a competitive advantage in the in the face of limited employment opportunities. College Students' personal knowledge requirement, knowledge collection, the establishment of personal knowledge system, knowledge management tools selection, knowledge assessment, innovation and application of knowledge, maintain and improve personal knowledge system that is college students personal knowledge management in the process of important aspects, it will improve the efficiency of several aspects of personal knowledge management of university students, to improve the competitive ability of the individual.
\end{abstract}

\section{Introduction}

At present, the difficult employment has become a big problem for college students. Facing the rigorous employment situation, almost all the students are aware of the same problem, that is the only improve their competitiveness in employment after graduation, will be a more confident, on the road to their dreams realized will go more stable solid. In order to improve the employment competitiveness of college students, only rely on knowledge, knowledge is absolutely not rely on rely on diploma, nor by the amount of knowledge you acquire now, don't think master certain knowledge can put things right once and for all to solve the problems in your life. College students rely on knowledge, refers to the knowledge basis, with the change of social environment, to determine their professional direction and fast learning knowledge, sharing knowledge, use knowledge innovation and value creation process, this process is the effective management of the process of knowledge of [1]. College students to improve their employability and competitiveness of effective management has become one of the most effective means of their own intellectual.

\section{Concept and the necessity of university students personal knowledge management}

A. The Concept of university students personal knowledge management

Personal knowledge management of university students is the students of knowledge, acquisition, storage, identification, use of learning, innovation of the management process, the purpose is to improve their innovation ability, strain capacity and speed of response, to enhance competitiveness of [2]. College Students' personal knowledge management objective is through the conscious, has the goal of knowledge learning and effective management of knowledge, as well as to the knowledge innovation and application, improve the personal value and competitiveness. From the content, students' self knowledge management includes the basic common sense, system science knowledge, professional knowledge, knowledge, knowledge of the industry trend, foreign language, computer knowledge, self management [3].

\section{B. The necessity of university students personal knowledge managementt}

College Students' personal knowledge management in general students can enhance individual competitiveness, is conducive to the growth and development of college students, in particular, can help students complete their studies successfully, can help students to establish a good image, help 
students quickly find their store of knowledge to solve problems, help to deepen and further accumulation of knowledge, can promote their competitiveness, help him more handy in employment, work, to improve the competitiveness of the destination [4]. College students effective management of knowledge, is the effective means of high ability and create employment competitiveness, for college students, knowledge management, also is the management of learning resources. In the University, students are exposed to all kinds of knowledge, through the personal knowledge management, the classification of the various data and information on their own, make all kinds of knowledge according to the need for transformation and utilization between implicit and explicit state, in the short term is to increase the knowledge reserves of its own, in the long run is in the job market to improve their competitiveness, cultivate the ability of lifelong learning, and ultimately contribute to their work, life.

\section{The implementation of personal knowledge management of University Students}

College students to effectively manage their knowledge, will enhance their employment competitiveness fundamentally, to manage their own knowledge, students can be carried out from the following aspects.

A. Enhance the personal knowledge management of university students consciousness, change the psychological inertia

American psychologist Bruner said: "the best motivation of learning, but to learn the knowledge itself interest." Personal knowledge management this sentence is also suitable for the college students, college students should attach importance to cultivating a strong desire for knowledge management, must consciously learning management knowledge and skills, to keep up with the pace of information technology development, advancing with the times, abandon that only science, too lazy to construct, sorting, processing, sharing, application and innovation of the old ways of thinking and practices on the knowledge, to be diligent to new ideas, new thinking, new ways of training in the knowledge management, and constantly develop intellectual resources, improve their own quality. Personal knowledge management itself is the embodiment of a process of subjective initiative, initiative means people have in practice consciousness, objective, independent, planning etc.. In the college students' personal knowledge, explicit knowledge are very small, most of the ingredients is tacit knowledge, if you can not take the initiative to management knowledge, it will lead to a substantial loss of information, also lost the formation of knowledge base, thus it is difficult to form a body of knowledge itself. The students only in knowledge management at the same time, continue to accumulate knowledge, personal ability will be improved. College students in the information technology environment, using Word, E-mail, a personal portal site, blog, QQ and other commonly used software for personal knowledge management, easy to stimulate their interest in learning and improve the active management of their knowledge awareness, to develop good habits, not only enhance the student's application ability of information technology, and the optimization of the learning effect [5].

B. Analysis of individual knowledge demand

Students must first analysis of the knowledge needs of their own, clearly the main demand of college students is the knowledge of the needs of occupation, is also for the future work and prepare knowledge, students can according to their own characteristics, carries on the analysis to the knowledge demand. Must first clear their orientation of knowledge, I can be what kind of work in the future; secondly, to the realistic effect of clear that knowledge; finally, to clear the cost of learning. Can the situation, adjust and modify the knowledge needs of their system. Knowledge is the basis of knowledge management, the lack of explicit knowledge requirement, we can't talk about knowledge management.

\section{Finishing the collection of knowledge}

Knowledge requirements determination after the course is to organize the knowledge collection, the collection process knowledge is far more complex than the application process of knowledge. First of all, we need to filter the redundant knowledge is not necessary, the relativity of knowledge, to judge the validity and authenticity, discarding irrelevant knowledge. Then, sorted according to 
the importance of knowledge, are processed in FIFO order. Finally, combined with the relevant knowledge, summed up the new knowledge, and put it into the students' knowledge system.

Knowledge acquisition, need to carry on their own knowledge, make its orderliness, ordering, namely knowledge organization. Knowledge organization is in accordance with the unity of knowledge, inclusive, cross and exclusive knowledge ordering, convenient for storage and use of knowledge. Knowledge organization is currently no organization method and system recognized, college students can build knowledge file system according to their own actual conditions. In order to long-term orderly knowledge management, must also establish certain standard to regulate and coordinate the knowledge content update, modify and share. Such as naming rules should be brief, clear, have uniqueness, so in the application of knowledge, it is convenient to search.

D. The establishment of personal knowledge system

To implement personal knowledge management objective is through purposeful, conscious management of personal knowledge, integration and complement, and gradually establish and perfect personal professional knowledge, improve work efficiency and competitiveness of the individual. College students in addition to the main learning materials, but also to be added without relates to or involving a large number of professional knowledge is not enough in the textbook, and straighten out the specialty knowledge system. Through the effective management of personal knowledge, scattered, fragmentary knowledge through the organization, management, systematize, become a practical, workable personal knowledge accumulation, to analyze their grasp of what knowledge, apply what knowledge, also need to know and learn what knowledge, and gradually establish and perfect personal knowledge system. Particular emphasis is in urgent knowledge directory we must carry on the collection of those unsolved knowledge, difficult but very important and urgent to facilitate the search for knowledge, and processing.

E. Reasonable choice of knowledge management tools

According to the knowledge demand and knowledge collection, knowledge classification after collection, to build their own knowledge system, is also a very important link to choose the personal knowledge management tool, students can according to their own kinds of knowledge management tools to master practical, select the appropriate knowledge management tools to manage their knowledge, such as Moodle platform, blog, Wiki, tree folder, webpage, special personal knowledge management software etc....... These can all be system of knowledge management. Of course, can also be a variety of tools selection to manage their knowledge, the classification of knowledge resources into personal knowledge management system, the establishment of personal knowledge system, for use in practical work and learning.

F. The assessment of knowledge

At any time for self assessment of their knowledge structure, which requires the students to obtain the knowledge from the external environment, including access to publish relevant information and the Internet recently published the latest knowledge. The knowledge system, combing the screening, orderly, and then has the knowledge and experience to do further analysis, so that the old and new knowledge naturally together, to integrate their knowledge so, through continuous accumulation, and ultimately improve their own knowledge system.

G. Innovation and application of knowledge

They have knowledge actively to communicate with the outside world, knowledge acquisition in order to in this process, and innovation. Knowledge management is a process of value creation, in the process of College Students' knowledge will continue to be updated, in particular environment, constantly release, explicit, acting on the external environment, so that the knowledge of their own social.

Knowledge exchange is one of the aspects of knowledge management. Knowledge communication can be sublimated and sharing, college students should take the initiative to their own knowledge to express sharing, a knowledge communication space of individual, and different people of different knowledge are discussed, for example, can participate in class discussions; of course, can also book letter or email to discuss individual; in addition, the new knowledge acquired to report, articles, books etc.. Process knowledge exchange can also be said to be the process of 
knowledge creation. In the process of knowledge exchange in the combination process, access to information and prior knowledge is created, knowledge communication is put forward their own point of view, get feedback, and then modify their ideas, theories, and repeat the process, new knowledge is created.

The application of knowledge is the process of knowledge and practice. Knowledge has certain effect or application space. In the application of space, application of knowledge is the knowledge verification. Most of the time, the reality of the world with the knowledge of the space is similar, if the copy theory of knowledge, the inevitable can not complete practice task, so we must modify knowledge, the creation of new knowledge for the new environment of space, the new environment contains new information, new information and have some knowledge of collision to form new theory, through practice, if verified, the formation of new knowledge creation and knowledge application, knowledge is inseparable from.

H. Maintain and improve personal knowledge system

The old knowledge constantly eliminated, new knowledge constantly, the change will knowledge system of college students, improve personal knowledge system is constantly in the learning process, students should continue to add new knowledge and the corresponding types of knowledge resources in the process of learning; update, modify or delete parts of knowledge resources sharing; adjustment set; knowledge resource for communication with others; constantly improve the standards of personal knowledge management; often to learn knowledge management experts blog or share the resources, have a look the experts is how the personal knowledge management research and practice. Only continue to maintain their own knowledge system, to establish a more reasonable and perfect knowledge system.

\section{Conclusion}

Students will step into the society, face the pressure and challenges of transition to employment status. Therefore, college students should not only learn the knowledge, more important is to learn how to acquire knowledge, how to manage knowledge, how to make knowledge play a role, in order to enter the society fully prepared. College Students' personal knowledge requirement, knowledge collection, the establishment of personal knowledge system, knowledge management tools selection, knowledge assessment, innovation and application of knowledge, maintain and improve personal knowledge system that is college students personal knowledge management in the process of important aspects, it will improve the efficiency of several aspects of personal knowledge management of University Students in order to improve the competitive ability, personal, lay a good foundation for the implementation of occupation ideal.

\section{References}

[1]Zhigang Tian,Need to Manage Your Knowledge[M]. Shenyang: Liaoning science and Technology Press, 2010.(3)23.

[2]Dongmei Lling,Yehong Shen, Students personal knowledge management methods [J]. Information technology development and economic, 2006(6)250-251.

[3]Shudiao Zhao,Yan Chen, College try and knowledge management [J].Science and education al-jamiat,2007(11)27-28.

[4]Kangmei Su,Construction of knowledge management model of college students from the perspective of the knowledge-based economy [J] Pioneering with science and technology, $2012(9) 97$.

[5]Chunmiao.Bi, Inquiry information technology environment of college students personal knowledge management strategy [J].Management information in China, 2011(1)76. 